\title{
Thoracic endovascular aortic repair for ruptured pseudocoarctation
}

\author{
Mamoru Arakawa, MD, PhD, ${ }^{\mathrm{a}}$ Koichi Yuri, MD, PhD, ${ }^{\mathrm{b}}$ Taro Takeuchi, $\mathrm{MD},{ }^{\mathrm{a}}$ and \\ Homare Okamura, MD, PhD, ${ }^{\mathrm{a}}$ Tokyo and Saitama, Japan
}

\footnotetext{
From the ${ }^{\mathrm{a} D e p a r t m e n t}$ of Cardiovascular Surgery, Nerima Hikarigaoka Hospital, Tokyo, Japan; and ${ }^{\mathrm{b}}$ Department of Cardiovascular Surgery, Saitama Medical Center, Jichi Medical University, Saitama, Japan. Disclosures: Authors have nothing to disclose with regard to commercial support.

Received for publication July 17, 2018; revisions received Aug 19, 2018; accepted for publication Sept 20, 2018; available ahead of print Nov 2, 2018.

Address for reprints: Mamoru Arakawa, MD, PhD, Department of Cardiovascular Surgery, Nerima Hikarigaoka Hospital, 2-11-1 Hikarigaoka, Nerima-Ku, Tokyo 179-0072, Japan (E-mail: a_mamoru@mbn.nifty.com). J Thorac Cardiovasc Surg 2019;157:e101-3 $0022-5223 / \$ 36.00$

Copyright (C) 2018 by The American Association for Thoracic Surgery https://doi.org/10.1016/j.jtcvs.2018.09.068
}

Video clip is available online.

Pseudocoarctation is a very rare congenital disease characterized by kinking at the level of the isthmus without pressure differences between the upper and lower limbs. ${ }^{1}$ There is no specific clinical feature of pseudocoarctation except for hypertension, which makes the diagnosis difficult. ${ }^{1}$ We report a rare case of spontaneous aortic rupture without aneurysm formation in a patient with pseudocoarctation treated with thoracic endovascular aortic repair (TEVAR).

\section{CASE REPORT}

A 38-year-old man presenting with back pain was referred to our institute. His past medical history included hypertension and adrenal adenoma. Contrast-enhanced computed tomography (CT) showed a kinked proximal descending aorta with a diameter of $35 \mathrm{~mm}$, left plural effusion, and posterior mediastinal mass surrounding the esophagus and descending aorta (Figure 1). No pressure difference was found between the upper and lower limbs. Upper endoscopy revealed no abnormal finding in the esophagus. He was diagnosed with pseudocoarctation based on the CT findings and blood pressure of the extremities. However, the diagnosis of aortic rupture was difficult to make because the patient had a small-sized aorta (Figure 1, A). CT scan performed on the day after admission showed increased pleural effusion with average Hounsfield unit of 59.3, which indicated active hemorrhage (Figure 2, $A, B$, and $C$ ). Despite the small diameter

\section{DISCUSSION} rupture. $^{1,2}$

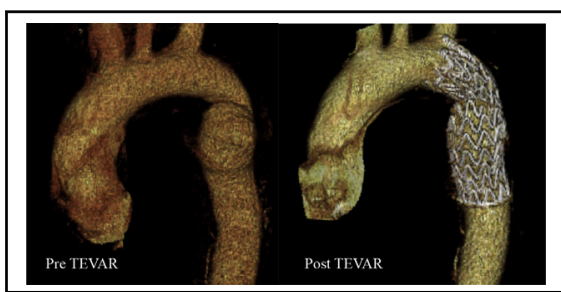

Ruptured pseudocoarctation treated with thoracic endovascular aortic repair.

Central Message

Pseudocoarctation may cause aortic rupture without aneurysm formation. Thoracic endovascular aortic repair for ruptured pseudocoarctation shows favorable treatment outcomes.

See Editorial Commentary e105.

of the proximal descending aorta, we suspected a ruptured descending aorta, and performed emergency TEVAR.

A $26 \times 100 \mathrm{~mm}$ conformable Gore TAG (cTAG) thoracic endoprosthesis (W. L. Gore and Associates, Flagstaff, Ariz) was placed through the left femoral artery without any complication. The postoperative course was uneventful. Contrast-enhanced CT performed on the second postoperative day showed no increase in pleural effusion and no endoleak. The pleural effusion and posterior mediastinal mass disappeared on the eighth postoperative day and the diagnosis of ruptured pseudocoarctation was confirmed (Figure 2, $D, E$, and $F$, and Video 1 ).

Pseudocoarctation is a very rare anomaly in which kinking of the aorta is not accompanied by a pressure gradient across the lesion. ${ }^{1}$ We report an extremely rare case with spontaneous ruptured pseudocoarctation treated with TEVAR. Some previous reports have discussed surgical repair of pseudocoarctation, including a case of aortic

The aortic wall fragility caused by pseudocoarctation may lead to aneurysm formation. ${ }^{1,3}$ However, the natural course of pseudocoarctation is unclear due to its infrequency, and treatment indication remains controversial. Makani and colleagues ${ }^{3}$ reported surgical repair via left thoracotomy for a patient with pseudocoarctation and multiple aneurysm formation. However, in 

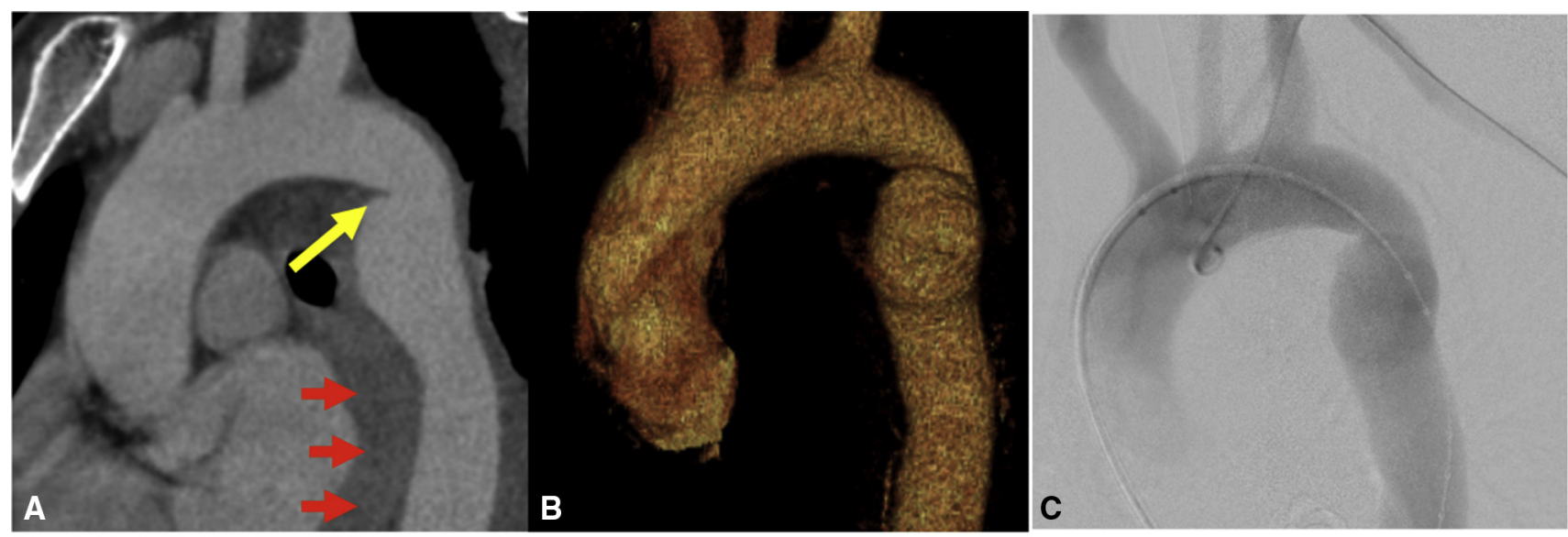

\section{Pre TEVAR}

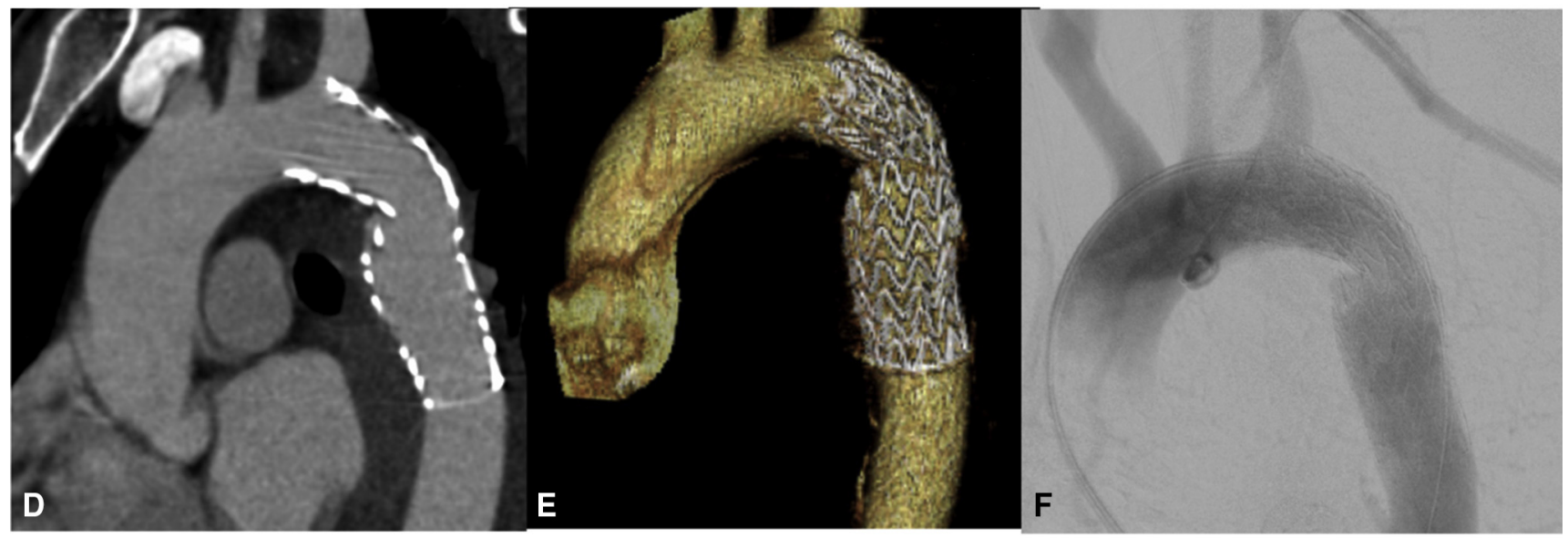

\section{Post TEVAR}

FIGURE 1. Images taken before thoracic endovascular repair (TEVAR). A, Computed tomography scan with multiplanar reconstruction showing kinking of the aorta (yellow arrow) and a mass surrounding the aorta and the esophagus (red arrows). B, Computed tomography scan with 3-dimensional volume rendering. C, Angiography during TEVAR before deployment. Images taken post-TEVAR. D, Computed tomography scan with multiplanar reconstruction. E, Computed tomography scan with 3-dimensional volume rendering. F, Angiography during TEVAR after deployment.

patients without aneurysm formation, continuous observation has been recommended. ${ }^{1}$ In our case, we conclusively diagnosed ruptured pseudocoarctation because pleural effusion and hematoma surrounding the descending aorta disappeared after TEVAR (Figure 2 and Video 1). It is noteworthy that, in patients with pseudocoarctation, the aorta can be ruptured even with a small aortic diameter.

Currently, TEVAR is available for treating various aortic pathologies such as true aneurysm, aortic dissection, traumatic aortic transection, and ruptured thoracic aortic aneurysm. ${ }^{4,5}$ In cases of pseudocoarctation, the extent of aortic lesion is limited, and TEVAR is a suitable treatment option. In our patient, we chose cTAG because it has the shortest available length of
$100 \mathrm{~mm}$ to prevent occlusion of the intercostal arteries, and a device with zero porosity prevents type IV leak. We successfully placed the cTAG with a single stiff wire. If the pseudocoarctation has extreme angulation, then the pull-through wire technique or a buddy wire may be required to deliver the device, or another kind of device with a soft sheath should be chosen for easier delivery.

\section{CONCLUSIONS}

Aortic rupture can develop in patients with pseudocoarctation, even with a small aortic diameter. In cases of ruptured pseudocoarctation, TEVAR should be the treatment of choice. 


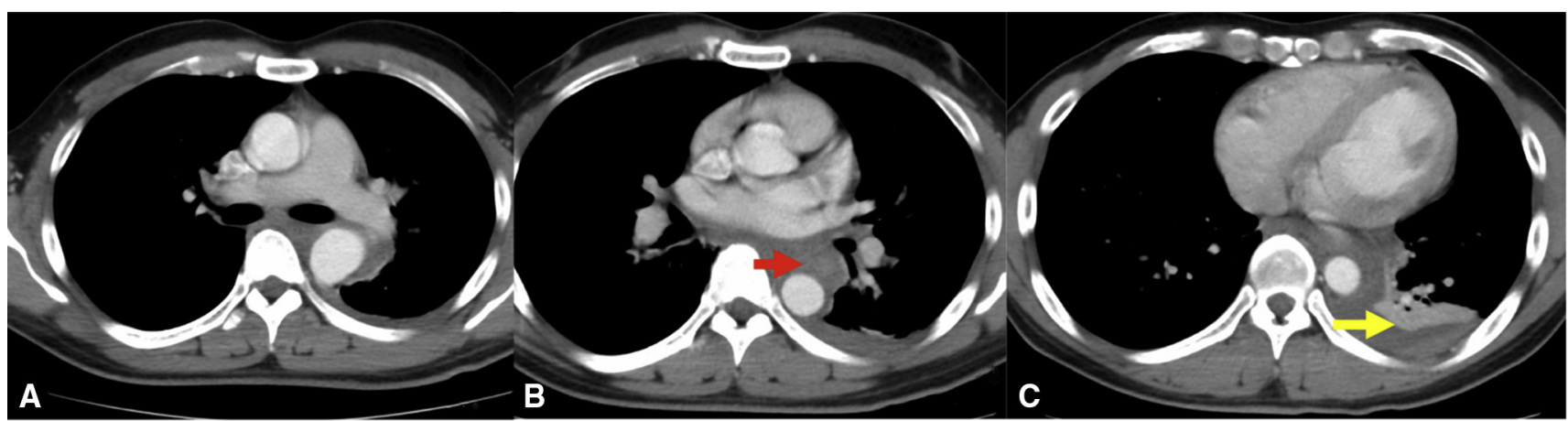

\section{Pre operation}

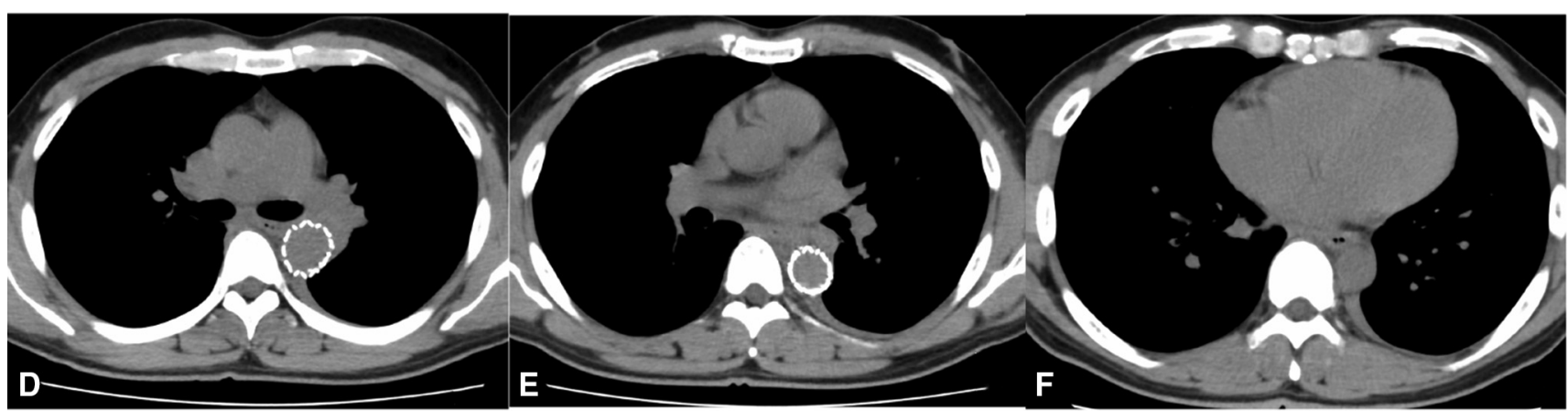

Post operative day 8

FIGURE 2. A-C, Axial views of preoperative computed tomography scan showing a mass surrounding the aorta and the esophagus (red arrow) and pleural effusion with computed tomography value suggestive of hemorrhage (yellow arrow). D-F, Eighth postoperative day computed tomography scans.

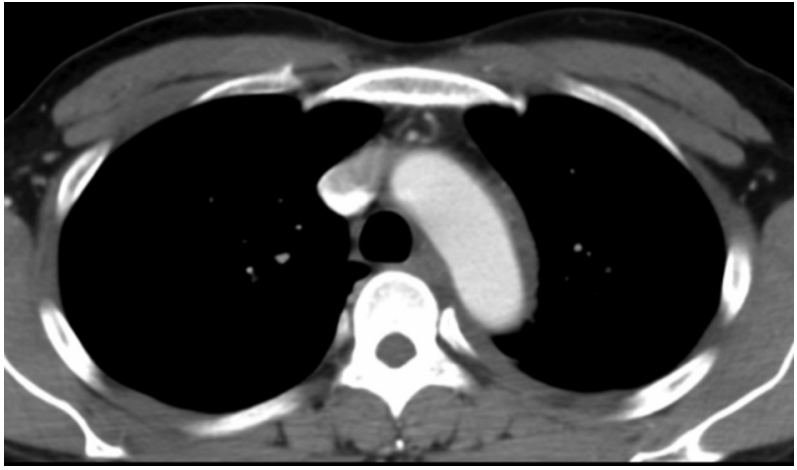

VIDEO 1. Computed tomography and angiography before and after thoracic endovascular repair. Video available at: https://www.jtcvs.org/ article/S0022-5223(18)32576-5/fulltext.

\section{References}

1. Singh S, Hakim FA, Sharma A, Roy RR, Panse PM, Chandrasekaran K, et al. Hy poplasia, pseudocoarctation and coarctation of the aorta-a systematic review. Heart Lung Circ. 2015;24:110-8.

2. Ikonomidis JS, Robbins RC. Cervical aortic arch with pseudocoarctation: presentation with spontaneous rupture. Ann Thorac Surg. 1999; 67:248-50.

3. Makani S, Mitchell J, Metton O, Di Filippo S, Henaine R, Ninet J. Surgical repai of a pseudocoarctation with cervical aortic arch complicated by multiple aneurysms of the aorta: a case report. Pan Afr Med J. 2017;26:236.

4. Steuer J, Wanhainen A, Thelin S, Nyman R, Eriksson MO, Björck M. Outcome of endovascular treatment of traumatic aortic transection. J Vasc Surg. 2012;56: 973-8

5. Makaroun MS, Dillavou ED, Wheatley GH, Cambria RP, Gore TAG Investigators. Five-year results of endovascular treatment with the Gore TAG device compared with open repair of thoracic aortic aneurysms. J Vasc Surg. 2008; 47:912-8. 